\title{
Coronary arterial complications after percutaneous coronary intervention in Behçet's disease
}

This article was published in the following Dove Press journal:

Research Reports in Clinical Cardiology

4 February 2013

Number of times this article has been viewed

\author{
Toshio Kinoshita' \\ Shinichiro Fujimoto' \\ Yukio Ishikawa ${ }^{2}$ \\ Hitomi Yuzawa' \\ Shunji Fukunaga' \\ Mikihito Toda ${ }^{3}$ \\ Kenji Wagatsuma ${ }^{3}$ \\ Yoshikiyo Akasaka ${ }^{2}$ \\ Toshiharu Ishii ${ }^{2}$ \\ Takanori Ikeda' \\ 'Department of Cardiovascular \\ Medicine, ${ }^{2}$ Department of Pathology, \\ ${ }^{3}$ Division of Interventional Cardiology, \\ Toho University Faculty of Medicine, \\ Ohta City, Tokyo, Japan
}

\begin{abstract}
Behçet's disease is a multisystemic vascular inflammatory disease, but concurrent cardiac diseases, such as acute myocardial infarction, are rare. Several complications may arise after coronary intervention for coronary lesions that interfere with treatment, and the incidence of coronary arterial complications due to invasive therapy remains unclear. Further, the longterm outcomes in patients with Behçet's disease after stenting for acute myocardial infarction have not been described. The present report describes a 35-year-old Japanese man with Behçet's disease who developed acute myocardial infarction. A coronary aneurysm developed at the stenting site of the left anterior descending coronary artery, along with stenosis in the left anterior descending segment proximal to the site. Although invasive therapy was considered, medication including immunosuppressants was selected because of the high risk of vascular complications after invasive therapy. The coronary artery disease has remained asymptomatic for the 4 years since the patient started medication. This case underscores the importance of considering the incidence of coronary arterial complications and of conservative treatment when possible.
\end{abstract}

Keywords: Behçet's disease, myocardial infarction, coronary arterial complications, percutaneous coronary intervention, immunosuppressants

\section{Introduction}

Behçet's disease is a multisystemic inflammatory disease characterized by recurrent oral aphthous ulcers, genital ulcers, uveitis, and skin lesions. ${ }^{1}$ Cardiac involvement in Behçet's disease is rare, and occurs at a rate of 6\%-8\%, among which myocardial infarction comprises $17.3 \%$. ${ }^{2,3}$ However, treatment for coronary lesions in Behçet's disease is often difficult, because coronary arterial complications frequently arise after coronary intervention. Thus, the most appropriate approach to treating coronary artery disease with Behçet's disease is controversial, and the long-term outcomes of coronary lesions in patients with this disease after stenting are unknown. This report describes the long-term outcome of a patient with Behçet's disease and acute myocardial infarction who developed a coronary aneurysm and stenosis after stenting.

\section{Case report}

A 35-year-old Japanese man was admitted to the coronary care unit with chest pain radiating to his left shoulder at rest persisting for one hour. The only coronary risk factor appeared to be smoking. He had no history of food, drug, or metal allergy. Examination on admission revealed weight $55 \mathrm{~kg}$, blood pressure 136/86 $\mathrm{mmHg}$, heart rate 67 beats per minute, and no signs of Behçet's disease. Electrocardiography revealed normal sinus rhythm, with ST segment elevation in
Correspondence:Toshio Kinoshita Toho University Faculty of Medicine, 6-I I-I Omori-Nishi, Ohta-City,

Tokyo, |43-854I, Japan

Tel $+8|337624| 5 \mid$

Fax +81337667810

Email kino-00039@med.toho-u.ac.jp
Research Reports in Clinical Cardiology 2013:4 9-12

(C) 2013 Kinoshita et al, publisher and licensee Dove Medical Press Ltd. This is an Open Access article

Dovepress

http://dx.doi.org/10.21 47/RRCC.S41240

which permits unrestricted noncommercial use, provided the original work is properly cited. 
leads V1-V5. He was diagnosed with acute myocardial infarction of the anterior wall and immediately underwent primary percutaneous coronary intervention. Coronary angiography demonstrated total occlusion of the proximal left anterior descending coronary artery (LAD, Figure 1A) and no significant lesions in the other arteries. Two stents (Driver $^{\circledR}$, Medtronic, Santa Rosa, CA; $3.0 \times 18 \mathrm{~mm}$, inflation pressure $10 \mathrm{~atm}$ ) were implanted in the LAD 2 hours after the onset of symptoms (Figure 1B). The peak value for creatine phosphokinase was 1247 IU/L. However, angiographic evidence of possible thrombus was seen in the left main stem coronary artery in spite of an intravenous bolus injection of heparin 5000 IU given just before the procedure. Follow-up coronary angiography was performed after 10 days of heparinization, and angiographic evidence of possible thrombus was no longer visible in the left main stem coronary artery, but a $3 \mathrm{~mm}$ aneurysm was seen on the LAD wall where the stent was implanted (Figure 1C). He was discharged on low-dose aspirin, an angiotensin-2 receptor antagonist, a beta-blocker, and a statin. Further follow-up coronary angiography for this aneurysm was scheduled for 2 months later.

One week after discharge, he was readmitted with fever and a skin rash. Physical examination revealed oral aphthous ulceration and dermal pseudofolliculitis, and a skin pathergy
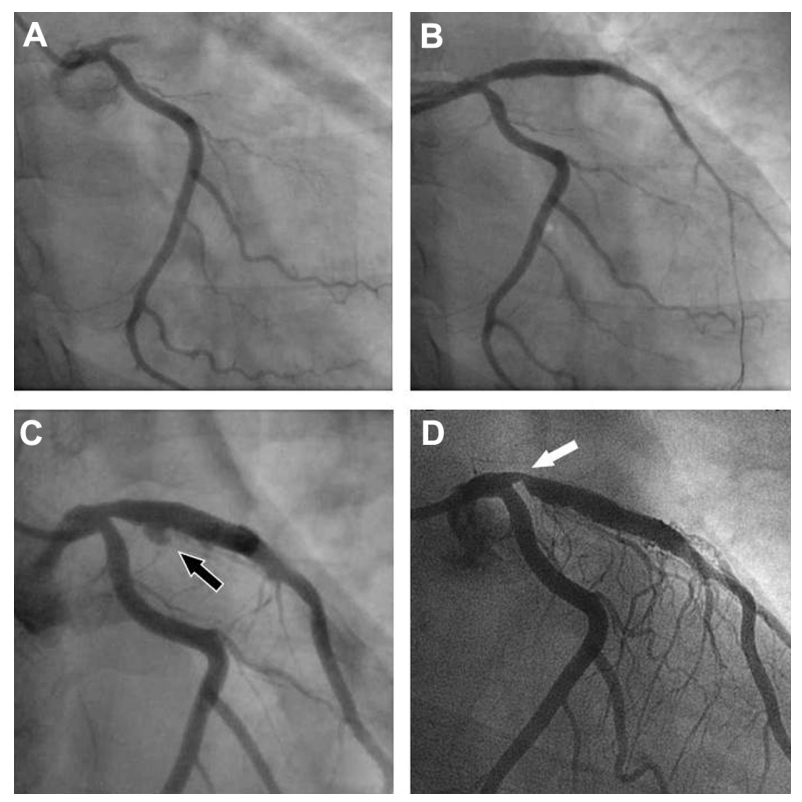

Figure I Coronary angiography upon admission shows total occlusion of the LAD (A). Two bare metal stents implanted in the LAD (B). Follow-up coronary angiography 10 days later shows a $3 \mathrm{~mm}$ aneurysm at the stent site in the LAD wall (C, black arrow). The aneurysm is no longer visible at the LAD stent site 2 months after stenting, but a new stenosis is evident in the proximal segment of the LAD (D, white arrow).

Abbreviation: $L A D$, left anterior descending artery.
Table I Coronary arterial complications after intervention for ACS in BD (1984-2012)

\begin{tabular}{|c|c|c|}
\hline \multirow{2}{*}{$\begin{array}{l}\text { ACS in BD patients } \\
\text { Intervention }\end{array}$} & \multicolumn{2}{|l|}{40 cases } \\
\hline & No of cases & $\begin{array}{l}\text { No of cases with } \\
\text { complications (\%) }\end{array}$ \\
\hline $\mathrm{PCl}$ & 12 & $6(50)$ \\
\hline POBA & 7 & \\
\hline Stenting (DES) & $5(1)$ & \\
\hline CABG (off pump-CABG) & II (3) & $2(18)$ \\
\hline
\end{tabular}

Abbreviations: ACS, acute coronary syndrome; BD, Behçet's disease; CABG, coronary artery bypass grafting; $\mathrm{DES}$, drug-eluting stent; $\mathrm{PCl}$, percutaneous coronary intervention; POBA, plain old balloon angioplasty.

test was positive. Hematology results showed the following: C-reactive protein $7.3 \mathrm{mg} / \mathrm{dL}$; white blood cells $13.9 \times 10^{3} / \mu \mathrm{L}$; and erythrocyte sedimentation rate $58 \mathrm{~mm} /$ hour. Gamma globulins, specific antibodies, and antineutrophil cytoplasmic antibodies were negative. He had a history of recurrent oral aphthous ulceration and dermal pseudofolliculitis. He was diagnosed as having Behçet's disease and treated with $30 \mathrm{mg}$ of prednisolone. HLA-B51 was negative. Melena appeared on hospital day 6 and colonoscopy revealed a punched-out ulcer in the terminal ileum, indicating intestinal Behçet's disease. We added mesalazine $3000 \mathrm{mg}$ and mercaptopurine hydrate $30 \mathrm{mg}$. Six weeks of this strategy improved his symptoms of fever and melena, and his elevated C-reactive protein, erythrocyte sedimentation rate, and white blood cells. Coronary angiography 2 months after identifying the coronary aneurysm demonstrated that the aneurysm was no longer visible at the LAD stent site, but a new 90\% stenosis had appeared in the proximal segment of the LAD (Figure 1D). Although percutaneous coronary intervention and bypass surgery were considered for treatment of this lesion, we opted for medical therapy because he had a high risk of arterial complications after invasive therapy, unstable Behçet's disease activity, with persistent oral aphthous ulceration but no chest pain. Infliximab $250 \mathrm{mg}$ every 8 weeks was added, and he was discharged on prednisolone $20 \mathrm{mg}$, mesalazine $3000 \mathrm{mg}$, and mercaptopurine hydrate $30 \mathrm{mg}$, along with the cardiovascular medications prescribed previously.

Stress Tc-tetrofosmin scintigraphy confirmed the continued absence of ischemia in his viable myocardium after the optimized medication listed on his discharge prescription. He made good progress with his Behçet's disease, and his coronary artery disease has remained asymptomatic in the 4 years since starting medication.

\section{Discussion}

Acute myocardial infarction in patients with Behçet's disease is rare, and the incidence of coronary arterial complications 
due to an invasive therapy remains unclear. Here we describe a patient with Behçet's disease and acute myocardial infarction in whom an aneurysm and proximal stenosis developed in the LAD after stenting. These arterial complications were treated conservatively and the patient was followed up for 4 years.

Although the incidence of coronary arterial involvement in Behçet's disease after percutaneous coronary intervention and coronary artery bypass grafting is unclear, it seems to be rather frequent. A search of the PubMed (US National Library of Medicine) online database between 1984 and 2012 yielded 40 patients with acute coronary syndrome, including unstable angina pectoris and acute myocardial infarction (see Table 1) ) $^{8-37}$ (these data originate from previous reports). Of these, 12 and 11 underwent percutaneous coronary intervention and coronary artery bypass grafting, respectively. Coronary arterial complications after percutaneous coronary intervention, including restenosis, reocclusion, coronary aneurysm, and repeated acute myocardial infarction, developed in six (50\%) of 12 patients, and two of these six patients underwent coronary artery bypass grafting as a second procedure. Percutaneous coronary intervention was performed in these 12 patients, seven of whom underwent plain old balloon angioplasty alone and five of whom underwent stenting with plain old balloon angioplasty. Complications were observed in two (18\%) of 11 patients after coronary artery bypass grafting as the primary treatment, and off-pump coronary artery bypass grafting was performed in three of the 11 patients. These data indicate that invasive treatment for coronary artery disease in patients with Behçet's disease is associated with a high complication rate. This might be because arterial complications attributable to coronary vasculitis are induced by activated leukocytes via oxidative stress and inflammatory cytokines. ${ }^{4}$

Our patient also developed an aneurysm in the LAD and high-grade stenosis in the proximal LAD after percutaneous coronary intervention. Given that the patient eventually became free of anginal symptoms and ischemia in the viable myocardium, conservative treatment was appropriate regardless of the severity of the LAD stenosis. However, if angina pectoris becomes unstable and ischemia in viable myocardium is extensive, then either percutaneous coronary intervention or coronary artery bypass grafting is indicated. Sismanoglu et al recommend no-touch techniques for the beating heart with arterial grafts in situ instead of free vein grafts and sequential anastomosis to reduce the number of aortic puncture sites in patients with Behçet's disease. ${ }^{5}$ Further, postoperative complications in both arteries and veins are significantly decreased in patients who receive immunosuppressants compared with those who do not. ${ }^{6}$ Our patient was at high risk for complications after invasive treatment of his coronary lesions. However, recent studies have indicated that anti-inflammatory agents, immunosuppressants, and anti-tumor necrosis factor- $\alpha$ agents are useful for preventing vascular complications arising after invasive procedures. ${ }^{6,7}$ Furthermore, the annual incidence of arterial events in patients with Behçet's disease decreases significantly after immunosuppressive therapy. ${ }^{6}$ Therefore, antiinflammatory agents and immunosuppressants might have played an important role in achieving a favorable outcome with regard to coronary arterial complications over the long term for our patient. Thus, avoidance of invasive procedures when possible is very important when treating coronary arterial complications in patients with Behçet's disease. If invasive procedures cannot be avoided, we strongly recommend that intervention be performed with good control of Behçet's disease activity.

\section{Acknowledgment}

This report was partly supported by a grant from the Strategic Research Foundation Grant-aided Project for Private schools at Heisei 23th from the Ministry of Education, Culture, Sports, Science and Technology of Japan, 2011-2015.

\section{Disclosure}

The authors report no conflicts of interest in this work.

\section{References}

1. Sakane T, Takeno M, Suzuki N, Inaba G. Behçet's disease. $N$ Engl J Med. 1999;341(17):1284-1291.

2. Geri G, Wechsler B, Thi Huong du L, et al. Spectrum of cardiac lesions in Behçet disease: a series of 52 patients and review of the literature. Medicine (Baltimore). 2012;91(1):25-34

3. Ideguchi H, Suda A, Takeno M, Ueda A, Ohno S, Ishigatsubo Y. Characteristics of vascular involvement in Behçet's disease in Japan: a retrospective cohort study. Clin Exp Rheumatol. 2011; 29(4 Suppl 67):S47-S53.

4. Kapsimali VD, Kanakis MA, Vaiopoulos GA, Kaklamanis PG. Etiopathogenesis of Behçet's disease with emphasis on the role of immunological aberrations. Clin Rheumatol. 2010;29(11):1211-1216.

5. Sismanoglu M, Omeroglu SN, Mansuroglu D, et al. Coronary artery disease and coronary artery bypass grafting in Behçet's disease. J Card Surg. 2005;20(2):160-163.

6. Saadoun D, Asli B, Wechsler B, et al. Long-term outcome of arterial lesions in Behçet disease: a series of 101 patients. Medicine (Baltimore) 2012;91(1):18-24.

7. Adler S, Baumgartner I, Villiger PM. Behçet's disease: successful treatment with infliximab in 7 patients with severe vascular manifestations. A retrospective analysis. Arthritis Care Res (Hoboken). 2012;64(4):607-611.

8. Hutchison SJ, Belch JJ. Behcet's syndrome presenting as myocardial infarction with impaired blood fibrinolysis. Br Heart $J$ 1984;52(6):686-687. 
9. Bowles CA, Nelson AM, Hammill SC, O’Duffy JD. Cardiac involvement in Behçet's disease. Arthritis Rheum. 1985;28(3):345-348.

10. Drobinski G, Wechsler B, Pavie A, et al. Emergency percutaneous coronary dilatation for acute myocardial infarction in Behcet's disease. Eur Heart J. 1987;8(10):1133-1136.

11. Le Thi Huong D, Wechsler B, Kahn JC, et al. [Myocardial infarction in Behçet's disease.] Arch Mal Coeur Vaiss. 1987;80(11):1663-1667. French.

12. Tamura Y, Matsuoka A, Ohtaki E, Okabe M, Shibata A. [Behcet's disease complicated by acute myocardial infarction treated with percutaneous transluminal coronary angioplasty.] Kokyu To Junkan. 1988;36(3):341-346. Japanese.

13. Kawakami Y, Nakayama Y, Nagao H, Hirota Y, Kawamura K. [A case of Behcet's disease complicated with acute myocardial infarction.] Kokyu To Junkan. 1991;39(9):935-938. Japanese.

14. Ioakimidis D, Georganas C, Panagoulis C, et al. A case of adamantiadisBehcet's syndrome presenting as myocardial infarction. Clin Exp Rheumatol. 1993;11(2):183-186.

15. Siepmann M, Kirch W. Coronary anomaly in Behcet's syndrome. Rheumatol Int. 1997;17(1):39-42.

16. Mori H, Okamura Y, Sugita Y, Mochizuki Y, Iida H, Shimada K. [A case of impending rupture of coronary aneurysm after rapid growth within a month.] Nihon Kyobu Geka Gakkai Zasshi. 1997;45(11):1848-1853. Japanese.

17. Ipek G, Omeroglu SN, Mansuroglu D, Kirali K, Uzun K, Sismanoglu M. Coronary artery bypass grafting in a 26-year-old man with total occlusion of the left main coronary artery related to behcet disease. J Thorac Cardiovasc Surg. 2001;122(6):1247-1249.

18. Putini RL, Natale E, Di Marcotullio G, De Felice F, Vajola SF. Acute coronary syndrome and late stent failure in a patient with Behcet's syndrome. Ital Heart J. 2003;4(4):281-284.

19. Schirmer M, Weidinger F, Sandhofer A, Gschwendtner A, Wiedermann C. Valvular disease and myocardial infarctions in a patient with Behcet disease. J Clin Rheumatol. 2003;9(5):316-320.

20. Hattori S, Kawana S. Behcet's syndrome associated with acute myocardial infarction. J Nippon Med Sch. 2003;70(1):49-52.

21. Kobayashi A, Sakata R, Kinjo T, Yotsumoto G, Matsumoto K, Iguro Y. Off-pump coronary artery bypass grafting in a patient with Behcet's disease. Jpn J Thorac Cardiovasc Surg. 2004;52(11):527-529.

22. Song MH, Watanabe T, Nakamura H. Successful off-pump coronary artery bypass for Behcet's disease. Ann Thorac Surg. 2004; 77(4):1451-1454.

23. Iyisoy A, Kursaklioglu H, Kose S, et al. Acute myocardial infarction and left subclavian artery occlusion in Behcet's disease: a case report. Mt Sinai J Med. 2004;71(5):330-334.
24. Kosar F, Sahin I, Gullu H, Cehreli S. Acute myocardial infarction with normal coronary arteries in a young man with the Behcet's disease. Int J Cardiol. 2005;99(2):355-357.

25. Kraiem S, Fennira S, Battikh K, Chehaibi N, Hmem M, Slimane ML. [Behcet disease: uncommon cause of myocardial infarction.] Ann Cardiol Angeiol (Paris). 2004;53(2):109-113. French.

26. Arishiro K, Nariyama J, Hoshiga M, et al. Vascular Behcet's disease with coronary artery aneurysm. Intern Med. 2006;45(15):903-907.

27. Sismanoglu M, Omeroglu SN, Mansuroglu D, et al. Coronary artery disease and coronary artery bypass grafting in Behcet's disease. $J$ Card Surg. 2005;20(2):160-163.

28. Calguneri M, Aydemir K, Ozturk MA, Haznedaroglu IC, Kiraz S, Ertenli I. Myocardial infarction and deep venous thrombosis in a young patient with behcet disease. Clin Appl Thromb Hemost. 2006;12(1):105-109.

29. Lee S, Lee CY, Yoo KJ. Acute myocardial infarction due to an unruptured sinus of Valsalva aneurysm in a patient with Behcet's syndrome. Yonsei Med J. 2007;48(5):883-885

30. Erbilen E, Albayrak S, Gulcan E, et al. Acute coronary stenosis in a young man with Behcet's syndrome. Med Princ Pract. 2008; 17(2): $157-160$

31. Sokhanvar S, Karimi M, Esmaeil-Zadeh A. Recurrent acute myocardial infarction with coronary artery aneurysm in a patient with Behcet's disease: a case report. J Med Case Rep. 2009;3:8869.

32. Ergelen M, Soylu O, Uyarel H, Yildirim A, Osmonov D, Orhan AL. Management of acute coronary syndrome in a case of Behcet's disease. Blood Coagul Fibrinolysis. 2009;20(8):715-718.

33. Harrison A, Abolhoda A, Ahsan C. Cardiovascular complications in Behcet syndrome: acute myocardial infarction with late stent thrombosis and coronary, ventricular, and femoral pseudoaneurysms. Tex Heart Inst J. 2009;36(5):498-500.

34. Balla S, Jariwala P, Gadepalli R, Prakash GS, N Verma NV, Chandra KS. A case of aneurysm of left anterior descending artery rupturing into right ventricular outflow tract presenting as acute anterior MI secondary to Behcet's syndrome. Indian Heart J. 2009;61(1):117-120.

35. Beyranvand MR, Namazi MH, Mohsenzadeh Y, Assadpour Piranfar M. Acute myocardial infarction in a patient with Behcet's disease. Arch Iran Med. 2009;12(3):313-316.

36. Sacre K, Ducrocq G, Hernigou A, Laissy JP, Papo T. Unusual cardiovascular events in Behcet's disease. Clin Exp Rheumatol. 2010; 28(4 Suppl 60):S82-S85.

37. Geri G, Wechsler B, Thi Huong du L, et al. Spectrum of cardiac lesions in Behcet disease: a series of 52 patients and review of the literature. Medicine (Baltimore). 2012;91(1):25-34.
Research Reports in Clinical Cardiology

\section{Publish your work in this journal}

Research Reports in Clinical Cardiology is an international, peerreviewed, open access journal publishing original research, reports, editorials, reviews and commentaries on all areas of cardiology in the clinic and laboratory. The manuscript management system is completely online and includes a very quick and fair peer-review system.

\section{Dovepress}

Visit http://www.dovepress.com/testimonials.php to read real quotes from published authors. 